\title{
Advances in Drug Design of Radiometal-Based Imaging Agents for Bone Disorders
}

\author{
Kazuma Ogawa ${ }^{1}$ and Hideo Saji ${ }^{2}$ \\ ${ }^{1}$ Division of Pharmaceutical Sciences, Graduate School of Natural Science and Technology, Kanazawa University, Kakuma-machi, \\ Kanazawa 920-1192, Japan \\ ${ }^{2}$ Department of Patho-Functional Bioanalysis, Graduate School of Pharmaceutical Sciences, Kyoto University, Kyoto 606-8501, Japan \\ Correspondence should be addressed to Kazuma Ogawa, kogawa@p.kanazawa-u.ac.jp
}

Received 5 August 2011; Accepted 26 September 2011

Academic Editor: Habib Zaidi

Copyright (๑) 2011 K. Ogawa and H. Saji. This is an open access article distributed under the Creative Commons Attribution License, which permits unrestricted use, distribution, and reproduction in any medium, provided the original work is properly cited.

\begin{abstract}
Nuclear medicine bone imaging has been the optimum diagnosis for the detection of bone disorders because the lesion could be detectable before the appearance of symptomatic and radiographic changes. Over the past three decades, ${ }^{99 \mathrm{~m}} \mathrm{Tc}-\mathrm{MDP}$ and ${ }^{99 \mathrm{~m}} \mathrm{Tc}-$ HMDP have been used as bone scintigraphic agents because of their superior biodistribution characteristics, although they are far from optimal from a chemical and pharmaceutical point of view. Recently, a more logical drug design has been proposed as a concept of bifunctional radiopharmaceuticals in which the carrier molecules (bisphosphonates) and radiometal chelating groups are separated within a molecule, specifically, ${ }^{99 \mathrm{~m}} \mathrm{Tc}$-mononuclear complex-conjugated bisphosphonate. Some of the ${ }^{99 \mathrm{~m}} \mathrm{Tc}$-mononuclear complex-conjugated bisphosphonate compounds showed superior biodistribution in preclinical studies. Moreover, the drug design concept could be applied to ${ }^{68} \mathrm{Ga}$ PET bone imaging agents. These studies would provide useful information for the development of radiometal-based imaging and therapeutic agents for bone disorders such as bone metastases.
\end{abstract}

\section{Background}

The skeleton is one of the most common organs to be affected by metastatic cancer. Carcinomas of the breast, lung, prostate, kidney, and thyroid have a tendency to easily metastasize to bone [1]. Although there has been significant advancement in imaging technologies, such as CT and MR, nuclear medicine bone imaging has been the optimum diagnosis for the detection of bone disorders, such as bone metastases, because of its high sensitivity. Namely, bone-seeking radiopharmaceuticals usually localize in skeletal lesions before the appearance of symptomatic and radiographic changes and the resulting easy evaluation of the entire skeleton [2]. This paper reviews currently available ${ }^{99 \mathrm{~m}} \mathrm{Tc}$ radiopharmaceuticals for bone scintigraphy and advances in drug design of radiometal-based bone-targeted compounds.

\section{2. ${ }^{99 m}$ Tc-Bisphosphonate Complexes}

Although some radiometals, such as lanthanide and rare earth, localize in bone by themselves, pertechnetate $\left.{ }^{99} \mathrm{mcO}_{4}^{-}\right)$hardly accumulates in bone by itself. Accordingly, a carrier for bone is necessary in order to take bone images with technetium. The first bone-seeking ${ }^{99 \mathrm{~m}} \mathrm{Tc}$ compound, a complex of reduced ${ }^{99 \mathrm{~m}} \mathrm{Tc}$ and sodium tripolyphosphate, was reported in 1971 [3], followed by a longchain linear polyphosphate [4] and pyrophosphate [5]. Pyrophosphate (Figure 1(a)) is composed of only two phosphate moieties and is the simplest polyphosphate. ${ }^{99 \mathrm{~m} T c-p y r o-}$ phosphate is now seldom used for skeletal imaging because of its high soft tissue background activity but is still employed to determine myocardial infarction. Unfortunately, pyrophosphate and polyphosphate are susceptible to in vivo degradation by enzymes such as alkaline phosphatases, resulting in the release of free technetium from the complexes. Subsequently, three groups almost simultaneously reported the ${ }^{99 \mathrm{~m}} \mathrm{Tc}$ complex of 1-hydroxyethyliden-1,1-diphosphonate (HEDP, Figure 1(b)) as a new bone imaging agent [6-8]. HEDP is one of the bisphosphonate (diphosphonate) compounds, which are known as compounds with high affinity for bone and inhibitors of bone resorption. Bisphosphonate compounds were synthesized with a $\mathrm{P}-\mathrm{C}-\mathrm{P}$ bonding 


$$
\begin{gathered}
\mathrm{OH} \\
\mathrm{O}=\stackrel{\mathrm{I}}{\mathrm{P}}-\mathrm{OH} \\
\mathrm{O} \\
\mathrm{O}=\stackrel{\mathrm{P}}{\mathrm{I}}-\mathrm{OH} \\
\mathrm{I} \mathrm{OH}
\end{gathered}
$$

(a)

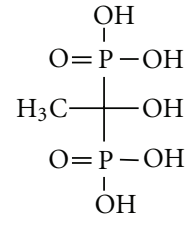

(b)

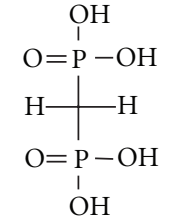

(c)

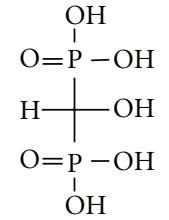

(d)
FIgURE 1: Chemical structures of bisphosphonates analogs (a) pyrophosphate, (b) HEDP, (c) MDP, and (d) HMDP.

sequence instead of the $\mathrm{P}-\mathrm{O}-\mathrm{P}$ sequence of pyrophosphate. Although these two chemical structures are similar, the P$\mathrm{C}-\mathrm{P}$ bond angles are smaller (117 degrees) than the P$\mathrm{O}-\mathrm{P}$ bond angles (128.7 degrees) and the P-C interatomic distance $(1.79 \AA)$ is longer than that of P-O (1.63 $\AA$ ) [9]. Bisphosphonate bonding is very stable chemically and affords greater resistance to in vivo phosphatase hydrolysis. As a result, ${ }^{99 \mathrm{~m}} \mathrm{Tc}-\mathrm{HEDP}$ exhibited more rapid clearance from blood and higher uptake in bone. In clinical study, ${ }^{99 \mathrm{~m}} \mathrm{Tc}$ HEDP showed significantly higher lesion-to-normal bone ratios when compared with either ${ }^{99 \mathrm{~m}} \mathrm{Tc}$-pyrophosphate or ${ }^{99 m}$ Tc-polyphosphate [10].

After introduction of ${ }^{99 m}$ Tc-methylene diphosphonate (MDP, Figure 1(c)) by Subramanian et al. [11] in 1975 and ${ }^{99 m}$ Tc-hydroxymethylene diphosphonate (HMDP, Figure 1(d)) by Bevan et al. [12] in 1980, ${ }^{99 m}$ Tc-MDP, and ${ }^{99 \mathrm{~m}}$ Tc-HMDP, which showed superior biodistribution compared to ${ }^{99 \mathrm{~m}} \mathrm{Tc}-\mathrm{HEDP}$, have been used as radiopharmaceuticals for bone scintigraphy for over thirty years [1315]. ${ }^{99 \mathrm{~m}} \mathrm{Tc}-\mathrm{MDP}$ is postulated to form a bidentate-bidentate bridge with hydroxyapatite while the presence of the hydroxyl group in ${ }^{99 \mathrm{~m}} \mathrm{Tc}$-HMDP would convert the ligand to form a bidentate-tridentate bridge and is expected to enhance the hydroxyapatite affinity of the ${ }^{99 \mathrm{~m}} \mathrm{Tc}$ complex $[12,16]$. However, the lower bone accumulation of ${ }^{99} \mathrm{~m}$ Tc-HEDP is not well understood because ${ }^{99 \mathrm{~m}} \mathrm{Tc}$-HEDP should also form bidentate-tridentate binding. Increasing steric hindrance associated with the methyl group at the central carbon atom of HEDP, the difference in solubility, and differences in molecular size as well as in the bisphosphonate polymeric complexes themselves have all been suggested $[12,17]$.

The accumulation of ${ }^{99 \mathrm{~m}} \mathrm{Tc}$-bisphoshonate complexes in bone must be derived from the coordination of bisphosphonate to calcium in the hydroxyapatite of bone, but the mechanism of high uptake to lesion sites in bone has not been completely elucidated. One factor should be the increased vascularity and regional distribution of blood flow that results from disease. However, it has been shown that regional bone blood flow alone does not account for the increased uptake of radiopharmaceuticals [18]. Other factors are involved in their binding and interaction with bone. It is generally assumed that ${ }^{99 \mathrm{~m}} \mathrm{Tc}$-bisphoshonate complexes accumulate at sites of active bone metabolism, that is to say, at areas of new bone formation or calcification $[19,20]$. It has also been reported that the accumulation mechanisms might be both adsorption onto the surface of hydroxyapatite in bone and incorporation into the crystalline structure of hydroxyapatite
[21]. Newly formed bone has a much larger surface area than does stable bone. That is, the crystalline structure of hydroxyapatite in newly formed bone is amorphous and has a greater surface area than that in normal bone [22]. An in vitro study demonstrated that bisphosphonate compounds have significantly higher adsorption on amorphous calcium phosphate than on crystalline calcium phosphate [17].

Bisphosphonate compounds form multiple complexes with reduced ${ }^{99 \mathrm{~m}} \mathrm{Tc}$. By using high-performance liquid chromatography (HPLC), the relative composition of ${ }^{99 \mathrm{~m}} \mathrm{Tc}$-bisphosphonate complexes in a reaction mixture has been found to vary with $\mathrm{pH}$ and with technetium, and with oxygen concentrations [23]. It has been postulated that ${ }^{99 \mathrm{~m}} \mathrm{Tc}-$ bisphosphonate complexes would be a mixture of monomers, oxo-bridged dimers, and oligomeric clusters with varying technetium-oxo core configurations, oxidation states, and ligand coordination numbers [24]. These radiolabeled species have different biodistribution properties. It was reported that the smallest, low-charged, mononuclear ${ }^{99 \mathrm{~m}}$ Tc-bisphosphonate complex has the greatest uptake in bone lesions and the highest lesion-to-muscle and lesion-to-normal bone ratios in experiments using each isolated complex by HPLC [25]. Thus, the exact structures and mechanisms of the action of ${ }^{99 \mathrm{~m}} \mathrm{Tc}$-labeled bisphosphonate remain uncertain.

\section{New Drug Design Concept of ${ }^{99 \mathrm{~m}}$ Tc-Labeled Bisphosphonate ( ${ }^{99 \mathrm{~m}} \mathrm{Tc}$ Complex-Conjugated Bisphosphonate Compounds)}

As mentioned above, despite over three decades of clinical use of ${ }^{99 \mathrm{~m}}$ Tc-bisphosphonate complexes, these radiopharmaceuticals are far from optimal from a chemical and pharmaceutical point of view. For example, their structures and compositions remain unknown because they cannot be obtained as a well-defined single-chemical species, but as mixtures of short-chain and long-chain oligomers. The biological behavior of this type of tracer is also affected by the different degrees of ionization and by variations in the relative amount of oligomers after preparation [23].

In addition, in clinical studies, an interval of 2 to 6 hours is required between an injection of ${ }^{99 \mathrm{~m}} \mathrm{Tc}$-labeled bisphosphonates and obtaining bone images [15]. Shortening this interval would lessen the burden to patients in terms of total examination length and radiation dose absorbed. To enable imaging at an earlier time after injection, a radiopharmaceutical with higher affinity for bone might be advantageous. Although the accumulation of bisphosphonate compounds in bone is achieved by binding the phosphonate groups with the $\mathrm{Ca}^{2+}$ of hydroxyapatite crystals [26], the phosphonate groups in ${ }^{99 \mathrm{~m}} \mathrm{Tc}-\mathrm{MDP}$ and ${ }^{99 \mathrm{~m}} \mathrm{Tc}-\mathrm{HMDP}$ serve as both coordinating ligands and $\mathrm{Ca}^{2+}$ binding functional groups [27], which might decrease the inherent accumulation of MDP and HMDP in bone.

Recently, to improve the ${ }^{99 \mathrm{~m}} \mathrm{Tc}$-labeled bisphosphonates currently used, a more logical drug design has been proposed based on the concept of bifunctional radiopharmaceuticals in which the carrier molecules (bisphosphonate) and radiometal chelating groups are separated within the molecule 


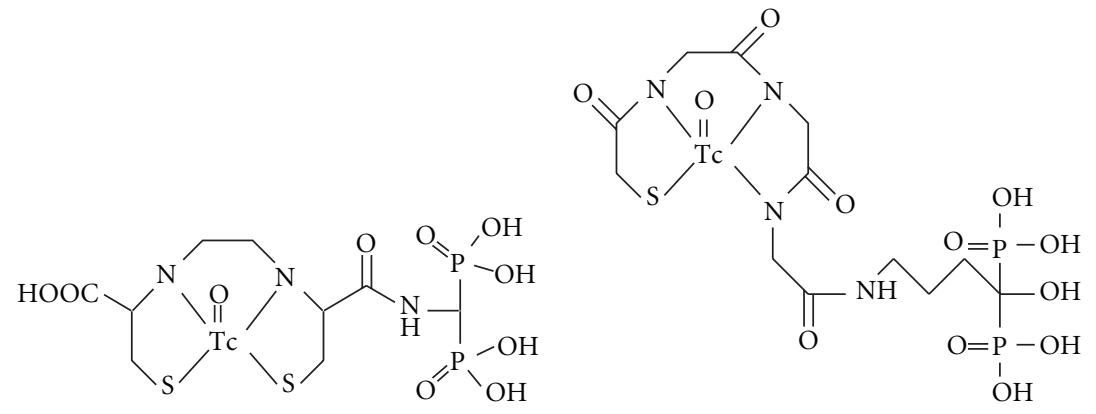

(a)

(b)

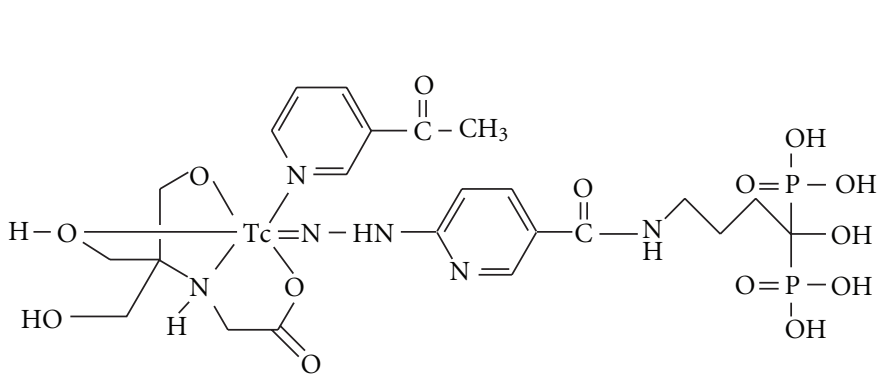

(c)<smiles></smiles>

(d)<smiles></smiles>

(e)

FIgure 2: Chemical structures of Tc-complex-conjugated bisphosphonate compounds (a) Tc-ECAMDP, (b) Tc-MAG3-HBP, (c) TcHYNIC-HBP, (d) $\left.\mathrm{Tc}(\mathrm{CO})_{3}\left(\kappa^{3}-\mathrm{pz}-\mathrm{BPOH}\right)\right]^{+}$, and (e) $\mathrm{Tc}(\mathrm{CO})_{3}$-DPA-alendronate.

so that they can each function independently and effectively. In particular, ${ }^{99 \mathrm{~m}} \mathrm{Tc}$-mononuclear complex-conjugated bisphosphonate compounds have been reported [28-31]. It was hypothesized that the bone affinity of ${ }^{99 \mathrm{~m}} \mathrm{Tc}$ labeled bisphosphonate would be enhanced by conjugating a stable mononuclear ${ }^{99 \mathrm{~m}} \mathrm{Tc}$ chelating group with a bisphosphonate moiety so that the conjugation does not impair the inherent chemical and biological properties of the bisphosphonate compounds. ${ }^{99 \mathrm{~m}} \mathrm{Tc}-\mathrm{L}, \mathrm{L}-\mathrm{ethylene}$ dicysteine (EC), ${ }^{99 \mathrm{~m}} \mathrm{Tc}$-mercaptoacetylglycylglycylglycine (MAG3), ${ }^{99 \mathrm{~m}} \mathrm{Tc}-6$-hydrazinonicotinic acid (HYNIC), ${ }^{99} \mathrm{~m}$ Tc-tricarbonyl anchored by pyrazolyl- (pz-) containing ligand, and ${ }^{99 \mathrm{~m}} \mathrm{Tc}$-tricarbonyl dipicolylamine (DPA) were selected as ${ }^{99 \mathrm{~m}} \mathrm{Tc}$ chelating molecules, and were conjugated with bisphosphonate compounds, ( ${ }^{99 \mathrm{~m}}$ Tc-ECAMDP, ${ }^{99 \mathrm{~m}} \mathrm{Tc}-\mathrm{MAG} 3-\mathrm{HBP},{ }^{99 \mathrm{~m}} \mathrm{Tc}-\mathrm{HYNIC}-\mathrm{HBP}$, $\left[{ }^{99 \mathrm{~m}} \mathrm{Tc}(\mathrm{CO})_{3}\left(\kappa^{3}-\mathrm{pz}-\mathrm{BPOH}\right)\right]^{+}$, and ${ }^{99 \mathrm{~m}} \mathrm{Tc}(\mathrm{CO})_{3}$-DPA-alendronate, resp., Figure 2).

In the drug design of the ${ }^{99 \mathrm{~m}} \mathrm{Tc}$-mononuclear complexconjugated bisphosphonate compounds, since these ligands contain a bisphosphonate site, there is a possibility that ${ }^{99 \mathrm{~m}} \mathrm{Tc}$ coordinates not with the proposed metal coordination moiety, such as EC, MAG3, and HYNIC but with the bisphosphonate moiety. To ascertain whether ${ }^{99 \mathrm{~m}} \mathrm{Tc}$ is chelated with only the proposed metal coordination moiety, some experiments were performed. For example, in the case of ${ }^{99 \mathrm{~m} T c-H Y N I C-H B P}$, ${ }^{99 \mathrm{~m}} \mathrm{Tc}-\mathrm{HYNIC}-\mathrm{HBP}$ was also prepared by the coupling of ${ }^{99 \mathrm{~m}} \mathrm{Tc}$-HYNIC previously complexed with the bisphosphonate site (prelabel method). RP-HPLC analysis revealed the ${ }^{99 \mathrm{~m}} \mathrm{Tc}-\mathrm{HYNIC}-\mathrm{HBP}$ by the prelabel method to be identical to that obtained from the labeling of HYNICHBP with ${ }^{99 \mathrm{~m}} \mathrm{Tc}$. These findings exclude the possibility of complexation between technetium and the bisphosphonate structure, and indicate the chelation of ${ }^{99 \mathrm{~m}} \mathrm{Tc}$ with the HYNIC moiety in HYNIC-HBP.

In these new compounds, ${ }^{99 m} \mathrm{Tc}-\mathrm{MAG} 3-\mathrm{HBP},{ }^{99 \mathrm{~m}} \mathrm{Tc}-$ HYNIC-HBP, and ${ }^{99 \mathrm{~m}} \mathrm{Tc}(\mathrm{CO})_{3}$-DPA-alendronate were investigated for in vitro hydroxyapatite binding as an index of bone affinity. ${ }^{99 \mathrm{~m} T c-M A G 3-H B P}$ and ${ }^{99 \mathrm{~m} T c-H Y N I C-H B P}$ showed a significantly higher rate of binding to hydroxyapatite than did ${ }^{99 \mathrm{~m}} \mathrm{Tc}-\mathrm{HMDP}$. ${ }^{99 \mathrm{~m}} \mathrm{Tc}(\mathrm{CO})_{3}$-DPA-alendronate showed a higher affinity to hydroxyapatite than did ${ }^{99 \mathrm{~m}} \mathrm{Tc}-$ MDP. At the same time, all new ${ }^{99 m} \mathrm{Tc}-\mathrm{mononuclear}$ 


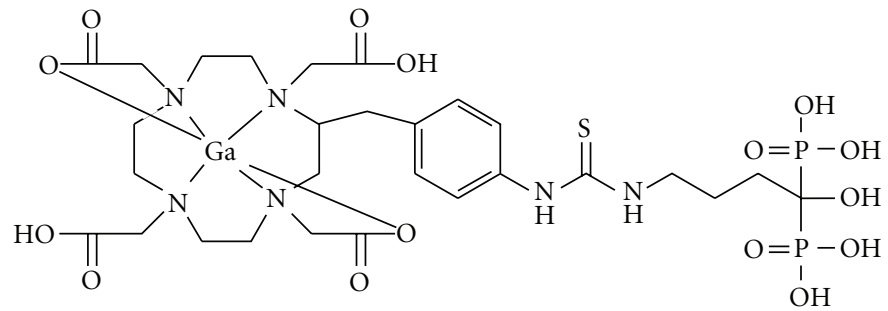

(a)

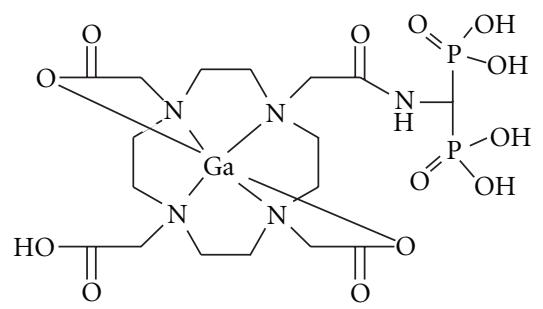

(b)

FIGURE 3: Chemical structures of radiogallium complex-conjugated bisphosphonate compounds (a) Ga-DOTA-Bn-SCN-HBP and (b) GaBPAMD.

complex-conjugated bisphosphonate compounds exhibited high bone uptake in in vivo animal experiments. ${ }^{99 \mathrm{~m}} \mathrm{Tc}-\mathrm{EC}-$ AMDP and ${ }^{99 m}$ Tc-HYNIC-HBP showed especially superior results; ${ }^{99 \mathrm{~m}} \mathrm{Tc}-\mathrm{EC}-\mathrm{AMDP}$ and ${ }^{99 \mathrm{~m}} \mathrm{Tc}-\mathrm{HYNIC}-\mathrm{HBP}$ showed significantly higher bone-to-blood ratios of radioactivity than did ${ }^{99 \mathrm{~m}} \mathrm{Tc}-\mathrm{MDP}$ and ${ }^{99 \mathrm{~m}} \mathrm{Tc}-\mathrm{HMDP}$.

\section{Radiogallium-Labeled Compounds as Bone Imaging Agents for PET}

${ }^{68} \mathrm{Ga}$ is one of the greatest practical and interesting radionuclides for clinical positron emission tomography (PET) because of its radiophysical properties $\left(T_{1 / 2}=68 \mathrm{~min}\right)$ [32]. ${ }^{68} \mathrm{Ga}$ is a generator-produced nuclide and can be eluted at any time on demand. Specifically, it does not require an on-site cyclotron. In principle, the long half-life of the parent nuclide ${ }^{68} \mathrm{Ge}\left(T_{1 / 2}=270.8\right.$ days $)$ provides a long life-span generator.

Investigations of ${ }^{68} \mathrm{Ga}$-labeled compounds for bone imaging were previously reported in the 1970s [33, 34]. In these reports, gallium was labeled with tripolyphosphate or ethylenediamine tetramethylene phosphonate (EDTMP) or diethylenetriamine pentamethylene phosphonate (DTPMP). These complexes showed high uptakes in bone. However, since use of the PET camera generally did not spread in the 1970 s and the quality of PET cameras was not high, the attention given to ${ }^{68} \mathrm{Ga}$ PET imaging agents was not so high.

For the last decade, ${ }^{68} \mathrm{Ga}$ as a nuclide has been considered a useful radionuclide for PET imaging. Thus, many ${ }^{68} \mathrm{Ga}-$ labeled compounds have been developed. Recently, ${ }^{68} \mathrm{Ga}-$ EDTMP was also reevaluated by Mitterhauser et al. [35]. However, they stated that the advantage of ${ }^{68} \mathrm{Ga}$-EDTMP over $\left[{ }^{18} \mathrm{~F}\right]$-fluoride was not apparent and that the future clinical prospect of ${ }^{68} \mathrm{Ga}$-EDTMP remained speculative.

The above-mentioned drug concept of stable mononuclear complex-conjugated bisphosphonate could be applicable to not only technetium complex radiopharmaceuticals but also to gallium radiopharmaceuticals. To develop a new PET tracer with radiogallium for imaging bone disorders such as bone metastases, 1,4,7,10-tetraazacyclododecane-1,4, 7,10 -tetraacetic acid (DOTA) was chosen as a chelating site because it has been well known that $\mathrm{Ga}$ forms a stable complex with DOTA. Therefore, Ga-DOTA-conjugated bisphosphonate compounds ( ${ }^{67} \mathrm{Ga}-\mathrm{DOTA}-\mathrm{Bn}-\mathrm{SCN}-\mathrm{HBP}$ and ${ }^{68} \mathrm{Ga}-\mathrm{BPAMD}$, Figure 3) have been developed [36, 37]. Actually, in biodistribution experiments, ${ }^{67} \mathrm{Ga}-\mathrm{DOTA}-\mathrm{Bn}-\mathrm{SCN}$ HBP rapidly accumulated in bone but was rarely observed in tissues other than bone. In addition, PET/CT imaging of bone metastases with ${ }^{68} \mathrm{Ga}$-BPAMD showed high uptake in osteoblastic metastases of human (Figure 4). The maximal standardized uptake was 77.1 and 62.1 in the 10th thoracic and L2 vertebra versus 39.1 and 39.2 for ${ }^{18}$ F-fluoride PET, respectively. These results suggest that the drug design concept of radiogallium complex-conjugated bisphosphonate could be useful for the development of ${ }^{68} \mathrm{Ga}$ PET imaging agents for bone disorders such as bone metastases.

\section{5. ${ }^{18}$ F-Fluoride as Bone Imaging Agent for PET}

${ }^{18}$ F-fluoride was initially reported by Blau et al. in 1962 [38]. After the development of ${ }^{99 \mathrm{~m}} \mathrm{Tc}$-labeled bone scintigraphy agents, such as ${ }^{99 \mathrm{~m}} \mathrm{Tc}-\mathrm{MDP},{ }^{18} \mathrm{~F}$-fluoride was replaced by them because the physical characteristics of ${ }^{99 \mathrm{~m}} \mathrm{Tc}$ were more convenient for imaging with conventional gamma cameras in those days. However, in the last decade, PET and PET/CT have evolved significantly and become widespread. The situation has similarly changed for ${ }^{68} \mathrm{Ga}$-labeled compounds. The changes caused the reemergence of ${ }^{18} \mathrm{~F}$-fluoride bone imaging with PET because current PET cameras have higher spatial resolution and greater sensitivity than conventional gamma cameras.

Like ${ }^{99 \mathrm{~m}} \mathrm{Tc}-\mathrm{MDP}$ as mentioned above, it is known that the distribution of ${ }^{18} \mathrm{~F}$-fluoride in bone also reflects both blood flow in bone and osteoblastic activity. Once ${ }^{18} \mathrm{~F}$-fluoride reaches the surface of the newly formed hydroxyapatite crystals, fluoride anions are isomorphously exchanged with the hydroxyl group in hydroxyapatite $\left(\mathrm{Ca}_{10}\left(\mathrm{PO}_{4}\right)_{6}(\mathrm{OH})_{2}\right)$ and fluorapatite $\left(\mathrm{Ca}_{10}\left(\mathrm{PO}_{4}\right)_{6} \mathrm{~F}_{2}\right)$ is formed [39]. A previous paper reported that electron probe $\mathrm{X}$-ray fluorescence studies on the topographical distribution of fluoride at the microscopic level in the iliac bone of an osteoporotic patient being treated with fluoride [40]. The results indicate that the distribution of ${ }^{18} \mathrm{~F}$-fluoride in newly mineralized bone is similar to that of ${ }^{99 \mathrm{~m}} \mathrm{Tc}-\mathrm{MDP}$.

There is an important difference between ${ }^{18} \mathrm{~F}$-fluoride and ${ }^{99 \mathrm{~m}} \mathrm{Tc}-\mathrm{MDP}$ in terms of their protein binding rates. ${ }^{18} \mathrm{~F}$ fluoride barely binds to serum protein [41] whereas ${ }^{99 \mathrm{~m}} \mathrm{Tc}$ MDP shows significant protein bindings. The difference in protein binding causes a difference in blood clearance between ${ }^{18} \mathrm{~F}$-fluoride and ${ }^{99 \mathrm{~m}} \mathrm{Tc}$-MDP. Hence, an interval of 2-3 hours is needed between an injection of ${ }^{99 \mathrm{~m}} \mathrm{Tc}-\mathrm{MDP}$ and bone imaging. In contrast, bone imaging can be performed less than 1 hour after an injection of ${ }^{18} \mathrm{~F}$-fluoride. Another 


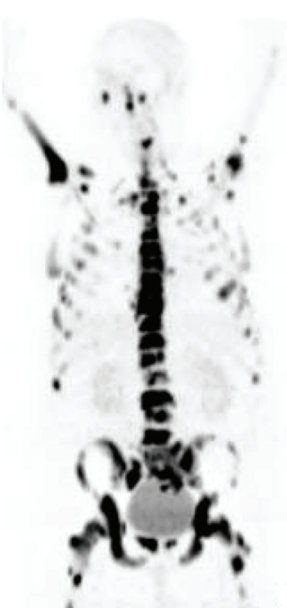

(a)

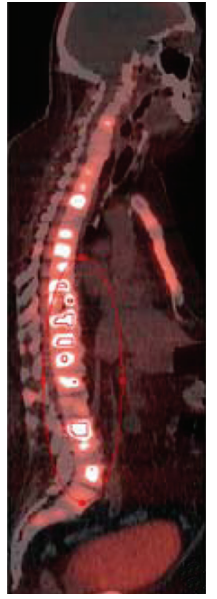

(b)

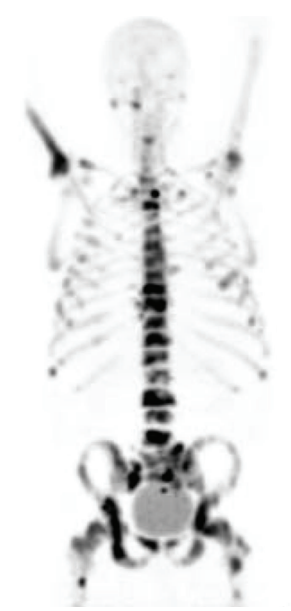

(c)

FIgURE 4: ${ }^{68} \mathrm{Ga}$-BPAMD was injected i.v. into a patient with known extensive bone metastases of prostate cancer. ${ }^{68} \mathrm{Ga}$-BPAMD (maximum intensity projection (MIP) $50 \mathrm{~min}$ after injection (p.i.), $462 \mathrm{MBq}$ ) revealed intense accumulation in multiple osteoblastic lesions in the central skeleton, ribs, and proximal extremities: (a) = coronal PET, (b) = sagittal PET/CT. For comparison, (c) shows ${ }^{18}$ F-fluoride PET (sagittal, MIP 90 min p.i., $270 \mathrm{MBq}$ ). With kind permission from Springer Science + Business Media: [36].

difference between ${ }^{18} \mathrm{~F}$-fluoride and ${ }^{99} \mathrm{~m}$ Tc-MDP is in terms of uptake to blood cells. ${ }^{18} \mathrm{~F}$-fluoride is taken up by red blood cells. The erythrocyte concentration of ${ }^{18} \mathrm{~F}$-fluoride is approximately $45-50 \%$ of the plasma concentration, namely, approximately $30 \%$ of total blood concentration. However, ${ }^{18} \mathrm{~F}$-fluoride is freely diffusible from red blood cells to the bone surface, so the uptake of ${ }^{18} \mathrm{~F}$-fluoride to red blood cells should not interfere with the accumulation of ${ }^{18} \mathrm{~F}$-fluoride in bone [41].

In clinical use in oncology, some papers reported on a comparison between ${ }^{18} \mathrm{~F}$-fluoride PET and planar ${ }^{99 \mathrm{~m}} \mathrm{Tc}$ MDP scintigraphy in the detection of bone metastases [42, 43]. ${ }^{18}$ F-fluoride PET was more sensitive in detecting bone metastases than planar ${ }^{99 \mathrm{~m}} \mathrm{Tc}-\mathrm{MDP}$ scintigraphy. However, the cause of increased sensitivity-whether it was derived from ${ }^{18} \mathrm{~F}$-fluoride itself as a tracer or because of the improved performance of the PET camera-could not be determined.

Specifically, ${ }^{18}$ F-fluoride PET has two important advantages in diagnosis imaging over planar ${ }^{99 \mathrm{~m}}$ Tc-MDP scintigraphy: superior sensitivity and a shorter interval between injection of a tracer and bone imaging. Thus, the use of ${ }^{18} \mathrm{~F}-$ fluoride could become common in the future.

\section{Conclusion}

Over the past three decades, ${ }^{99 \mathrm{~m}} \mathrm{Tc}-\mathrm{MDP}$ and ${ }^{99 \mathrm{~m}} \mathrm{Tc}-\mathrm{HMDP}$ have been used for detecting bone metastases, although their mechanisms of accumulation remain uncertain. Recent efforts of chelate-conjugated bisphosphonates and their derivatives have provided chemically well-characterized new ${ }^{99 \mathrm{~m}}$ Tc-labeled bone-seeking tracers. Furthermore, the drug design concept could be applied to ${ }^{68} \mathrm{Ga}$ PET bone imaging agents. These studies would provide useful information for the development of radiometal-based imaging and therapeutic agents for bone disorders such as bone metastases.

\section{References}

[1] R. E. Coleman, "Skeletal complications of malignancy," Cancer, vol. 80, no. 8, pp. 1588-1594, 1997.

[2] A. Z. Krasnow, R. S. Hellman, M. E. Timins, B. D. Collier, T. Anderson, and A. T. Isitman, "Diagnostic bone scanning in oncology," Seminars in Nuclear Medicine, vol. 27, no. 2, pp. 107-141, 1997.

[3] G. Subramanian and J. G. McAfee, "A new complex of ${ }^{99 \mathrm{~m}} \mathrm{Tc}$ for skeletal imaging," Radiology, vol. 99, no. 1, pp. 192-196, 1971.

[4] G. Subramanian, J. G. McAfee, E. G. Bell, R. J. Blair, R. E. O'Mara, and P. H. Ralston, "99m Tc-labeled polyphosphate as a skeletal imaging agent," Radiology, vol. 102, no. 3, pp. 701704, 1972.

[5] J. W. Fletcher, E. Solaric George, R. E. Henry, and R. M. Donati, "Evaluation of ${ }^{99 \mathrm{~m}} \mathrm{Tc}$ pyrophosphate as a bone imaging agent," Radiology, vol. 109, no. 2, pp. 467-469, 1973.

[6] G. Subramanian, J. G. McAfee, R. J. Blair, A. Mehter, and T. Connor, " $99 \mathrm{~m}$ Tc-EHDP: a potential radiopharmaceutical for skeletal imaging," Journal of Nuclear Medicine, vol. 13, no. 12, pp. 947-950, 1972.

[7] F. P. Castronovo and R. J. Callahan, "New bone scanning agent: ${ }^{99 \mathrm{~m}} \mathrm{Tc}$-labeled 1-hydroxy-ethylidene-1, 1-disodium phosphonate," Journal of Nuclear Medicine, vol. 13, no. 11, pp. 823-827, 1972.

[8] Y. Yano, J. McRae, D. C. Van Dyke, and H. O. Anger, "Technetium-99m-labeled stannous ethane-1-hydroxy-1 1-diphosphonate: a new bone scanning agent," Journal of Nuclear Medicine, vol. 14, no. 2, pp. 73-78, 1973.

[9] M. Larsen, R. Willett, and R. G. Yount, "Imidodiphosphate and pyrophosphate: possible biological significance of similar structures," Science, vol. 166, no. 3912, pp. 1510-1511, 1969.

[10] D. L. Citrin, R. G. Bessent, J. B. Tuohy et al., "A comparison of phosphate bone-scanning agents in normal subjects and patients with malignant disease," The British Journal of Radiology, vol. 48, pp. 118-121, 1975.

[11] G. Subramanian, J. G. McAfee, and R. J. Blair, "Technetium $99 \mathrm{~m}$ methylene diphosphonate: a superior agent for skeletal 
imaging: comparison with other technetium complexes," Journal of Nuclear Medicine, vol. 16, no. 8, pp. 744-755, 1975.

[12] J. A. Bevan, A. J. Tofe, and J. J. Benedict, "Tc-99m HMDP (hydroxymethylene diphosphonate): a radiopharmaceutical for skeletal and acute myocardial infarct imaging. I. Synthesis and distribution in animals," Journal of Nuclear Medicine, vol. 21, no. 10, pp. 961-966, 1980.

[13] P. A. Domstad, J. J. Coupal, E. E. Kim, J. S. Blake, and F. H. DeLand, "99m Tc-hydroxymethane diphosphonate: a new bone imaging agent with a low tin content," Radiology, vol. 136, pp. 209-211, 1980.

[14] C. Mari, A. Catafau, and I. Carrio, "Bone scintigraphy and metabolic disorders," Quarterly Journal of Nuclear Medicine, vol. 43, no. 3, pp. 259-267, 1999.

[15] C. Love, A. S. Din, M. B. Tomas, T. P. Kalapparambath, and C. J. Palestro, "Radionuclide bone imaging: an illustrative review," Radiographics, vol. 23, no. 2, pp. 341-358, 2003.

[16] S. S. Jurisson, J. J. Benedict, R. C. Elder, R. Whittle, and E. Deutsch, "Calcium affinity of coordinated diphosphonate ligands. Single-crystal structure of $\left[(\text { en })_{2} \mathrm{Co}\left(\mathrm{O}_{2} \mathrm{P}(\mathrm{OH}) \mathrm{CH}_{2} \mathrm{P}(\mathrm{OH}) \mathrm{O}_{2}\right)\right] \mathrm{ClO}_{4} \cdot \mathrm{H}_{2} \mathrm{O}$. Implications for the chemistry of technetium-99m-diphosphonate skeletal imaging agents," Inorganic Chemistry, vol. 22, no. 9, pp. 1332-1338, 1983.

[17] M. D. Francis, D. L. Ferguson, and A. J. Tofe, "Comparative evaluation of three diphosphonates: in vitro adsorption (C-14 labeled) and in vivo osteogenic uptake (Tc-99m complexed)," Journal of Nuclear Medicine, vol. 21, no. 12, pp. 1185-1189, 1980.

[18] J. P. Lavender, R. A. A. Khan, and S. P. F. Hughes, "Blood flow and tracer uptake in normal and abnormal canine bone: comparisons with Sr-85 microspheres, $\mathrm{Kr}-81 \mathrm{~m}$, and Tc-99m MDP," Journal of Nuclear Medicine, vol. 20, no. 5, pp. 413-418, 1979.

[19] R. S. Budd, G. S. Hodgson, and W. S. C. Hare, "The relation of radionuclide uptake by bone to the rate of calcium mineralization. I: experimental studies using ${ }^{45} \mathrm{Ca},{ }^{32} \mathrm{P}$ and ${ }^{99} \mathrm{Tc}^{\mathrm{m}}$-MDP," British Journal of Radiology, vol. 62, no. 736, pp. 314-317, 1989.

[20] R. S. Budd, G. S. Hodgson, and W. S. C. Hare, "The relation of radionuclide uptake by bone to the rate of calcium mineralization. II: patient studies using ${ }^{99} \mathrm{Tcm}-\mathrm{MDP}, "$ British Journal of Radiology, vol. 62, no. 736, pp. 318-320, 1989.

[21] D. Kanishi, "99m Tc-MDP accumulation mechanisms in bone," Oral Surgery Oral Medicine and Oral Pathology, vol. 75, no. 2, pp. 239-246, 1993.

[22] C. S. B. Galasko, "Mechanism of uptake of bone imaging isotopes by skeletal metastases," Clinical Nuclear Medicine, vol. 5, no. 12, pp. 565-568, 1980.

[23] S. Tanabe, J. P. Zodda, and E. Deutsch, "Effect of pH on the formation of $\mathrm{Tc}(\mathrm{NaBH} 4)-\mathrm{MDP}$ radiopharmaceutical analogues," International Journal of Applied Radiation and Isotopes, vol. 34, no. 12, pp. 1577-1584, 1983.

[24] G. M. Wilson and T. C. Pinkerton, "Determination of charge and size of technetium diphosphonate complexes by anionexchange liquid chromatography," Analytical Chemistry, vol. 57, no. 1, pp. 246-253, 1985.

[25] T. C. Pinkerton, K. T. Cheng, S. M. Shaw, and G. M. Wilson, "Influence of complex charge and size on the uptake of ${ }^{99 \mathrm{~m}} \mathrm{Tc}$ diphosphonates in osteogenic tissue," International Journal of Radiation Applications and Instrumentation, vol. 13, no. 1, pp. 49-56, 1986.
[26] J. L. Meyer and G. H. Nancollas, "The influence of multidentate organic phosphonates on the crystal growth of hydroxyapatite," Calcified Tissue International, vol. 13, no. 4, pp. 295-303, 1973.

[27] K. Libson, E. Deutsch, and B. L. Barnett, "Structural characterization of a $99 \mathrm{Tc}$-diphosphonate complex. Implications for the chemistry of $99 \mathrm{mTc}$ skeletal imaging agents," Journal of the American Chemical Society, vol. 102, no. 7, pp. 2476-2478, 1980.

[28] K. Verbeke, J. Rozenski, B. Cleynhens et al., "Development of a conjugate of ${ }^{99 \mathrm{~m}} \mathrm{Tc}-\mathrm{EC}$ with aminomethylenediphosphonate in the search for a bone tracer with fast clearance from soft tissue," Bioconjugate Chemistry, vol. 13, no. 1, pp. 16-22, 2002.

[29] K. Ogawa, T. Mukai, Y. Inoue, M. Ono, and H. Saji, "Development of a novel ${ }^{99 \mathrm{~m}} \mathrm{Tc}$-chelate-conjugated bisphosphonate with high affinity for bone as a bone scintigraphic agent," Journal of Nuclear Medicine, vol. 47, no. 12, pp. 2042-2047, 2006.

[30] E. Palma, B. L. Oliveira, J. D. G. Correia et al., "A new bisphosphonate-containing ${ }^{99 \mathrm{~m}} \mathrm{Tc}(\mathrm{I})$ tricarbonyl complex potentially useful as bone-seeking agent: synthesis and biological evaluation," Journal of Biological Inorganic Chemistry, vol. 12, no. 5, pp. 667-679, 2007.

[31] R. Torres Martin De Rosales, C. Finucane, S. J. Mather, and P. J. Blower, "Bifunctional bisphosphonate complexes for the diagnosis and therapy of bone metastases," Chemical Communications, no. 32, pp. 4847-4849, 2009.

[32] K. P. Zhernosekov, D. V. Filosofov, R. P. Baum et al., "Processing of generator-produced ${ }^{68} \mathrm{Ga}$ for medical application," Journal of Nuclear Medicine, vol. 48, no. 10, pp. 1741-1748, 2007.

[33] R. T. Goulet, A. Shysh, A. A. Noujaim, and B. C. Lentle, "Investigation of ${ }^{68} \mathrm{Ga}$ tripolyphosphate as a potential bone scanning agent," International Journal of Applied Radiation and Isotopes, vol. 26, no. 4, pp. 195-199, 1975.

[34] M. K. Dewanjee, D. J. Hnatowich, and R. Beh, "New ${ }^{68} \mathrm{Ga}$ labeled skeletal imaging agents for positron scintigraphy," Journal of Nuclear Medicine, vol. 17, no. 11, pp. 1003-1007, 1976.

[35] M. Mitterhauser, S. Toegel, W. Wadsak et al., "Pre vivo, ex vivo and in vivo evaluations of $\left[{ }^{68} \mathrm{Ga}\right]$-EDTMP," Nuclear Medicine and Biology, vol. 34, no. 4, pp. 391-397, 2007.

[36] M. Fellner, R. P. Baum, V. Kubíček et al., "PET/CT imaging of osteoblastic bone metastases with $68 \mathrm{Ga}$ - bisphosphonates: first human study," European Journal of Nuclear Medicine and Molecular Imaging, vol. 37, no. 4, p. 834, 2010.

[37] K. Ogawa, K. Takai, H. Kanbara et al., "Preparation and evaluation of a radiogallium complex-conjugated bisphosphonate as a bone scintigraphy agent," Nuclear Medicine and Biology, vol. 38, no. 5, pp. 631-636, 2011.

[38] M. Blau, W. Nagler, and M. A. Bender, "Fluorine-18: a new isotope for bone scanning," Journal of Nuclear Medicine, vol. 3, pp. 332-334, 1962.

[39] A. G. Jones, M. D. Francis, and M. A. Davis, "Bone scanning: radionuclidic reaction mechanisms," Seminars in Nuclear Medicine, vol. 6, no. 1, pp. 3-18, 1976.

[40] S. Bang and C. A. Baud, "Topographical distribution of fluoride in iliac bone of a fluoride-treated osteoporotic patient," Journal of Bone and Mineral Research, vol. 5, no. 1, pp. S87S89, 1990.

[41] G. M. Blake, S. J. Park-Holohan, G. J. R. Cook, and I. Fogelman, "Quantitative studies of bone with the use of ${ }^{18} \mathrm{~F}$ fluoride and $99 \mathrm{~m}$ Tc-methylene diphosphonate," Seminars in Nuclear Medicine, vol. 31, no. 1, pp. 28-49, 2001.

[42] H. Schirrmeister, A. Guhlmann, K. Elsner et al., "Sensitivity in detecting osseous lesions depends on anatomic localization: 
planar bone scintigraphy versus ${ }^{18} \mathrm{~F}$ PET," Journal of Nuclear Medicine, vol. 40, no. 10, pp. 1623-1629, 1999.

[43] H. Schirrmeister, A. Guhlmann, J. Kotzerke et al., "Early detection and accurate description of extent of metastatic bone disease in breast cancer with fluoride ion and positron emission tomography," Journal of Clinical Oncology, vol. 17, no. 8, pp. 2381-2389, 1999. 


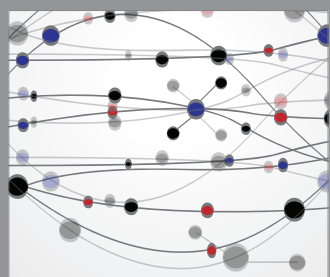

The Scientific World Journal
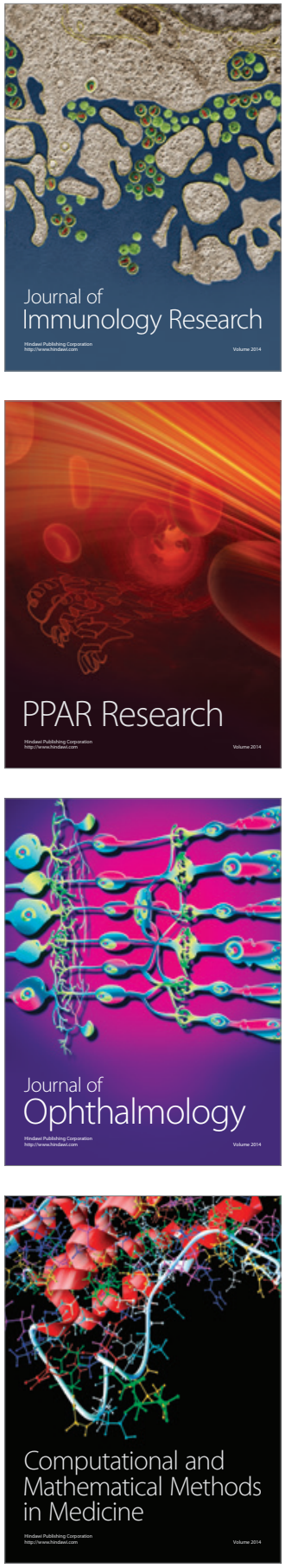

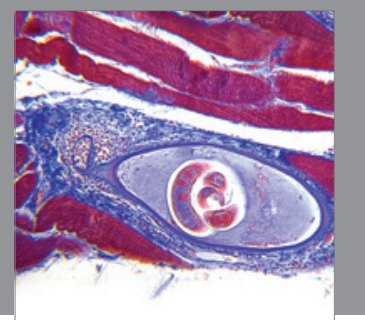

Gastroenterology

Research and Practice
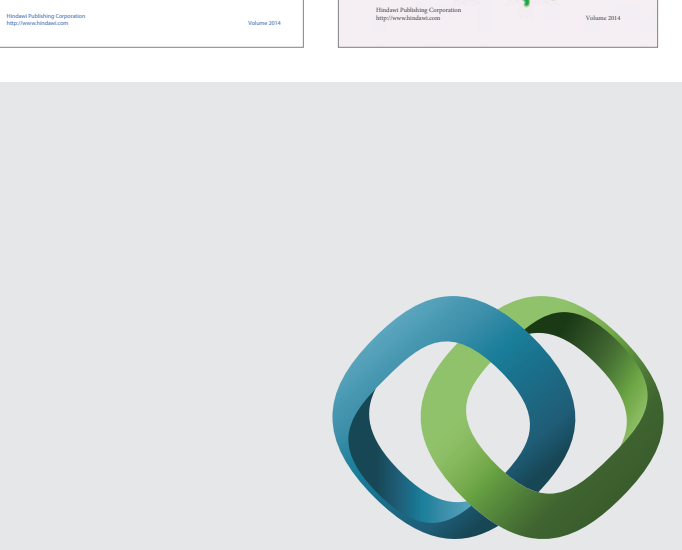

\section{Hindawi}

Submit your manuscripts at

http://www.hindawi.com
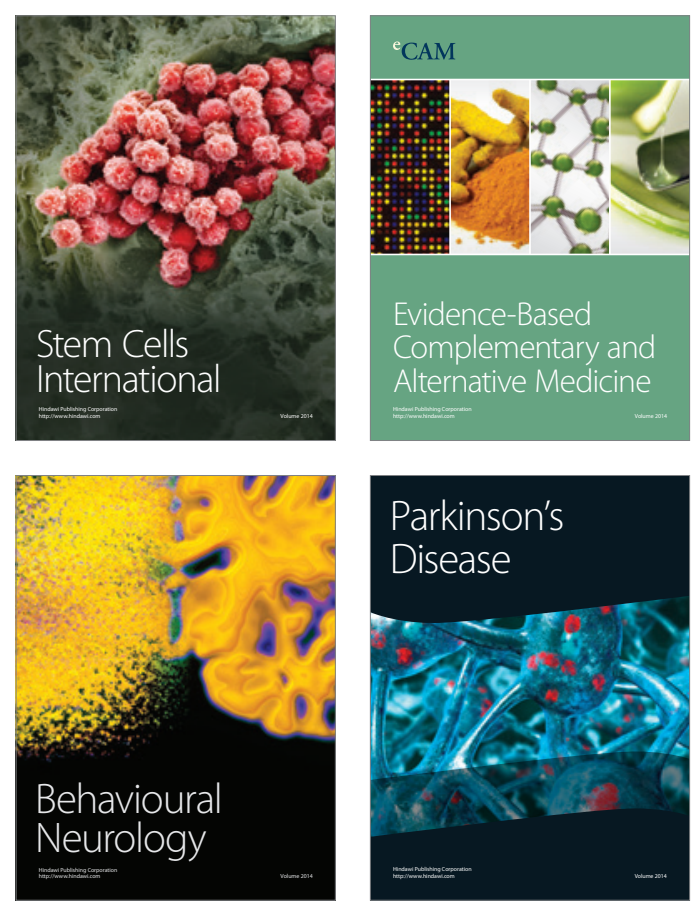

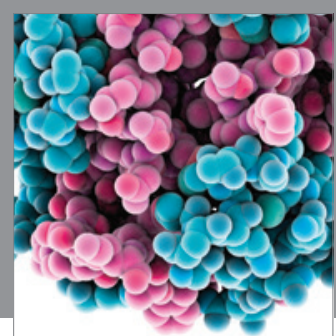

Journal of
Diabetes Research

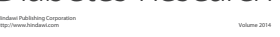

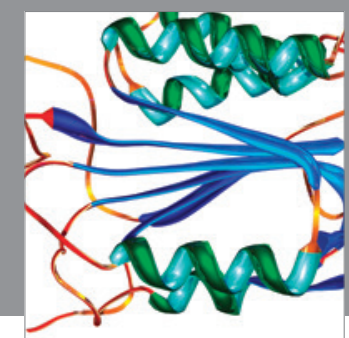

Disease Markers
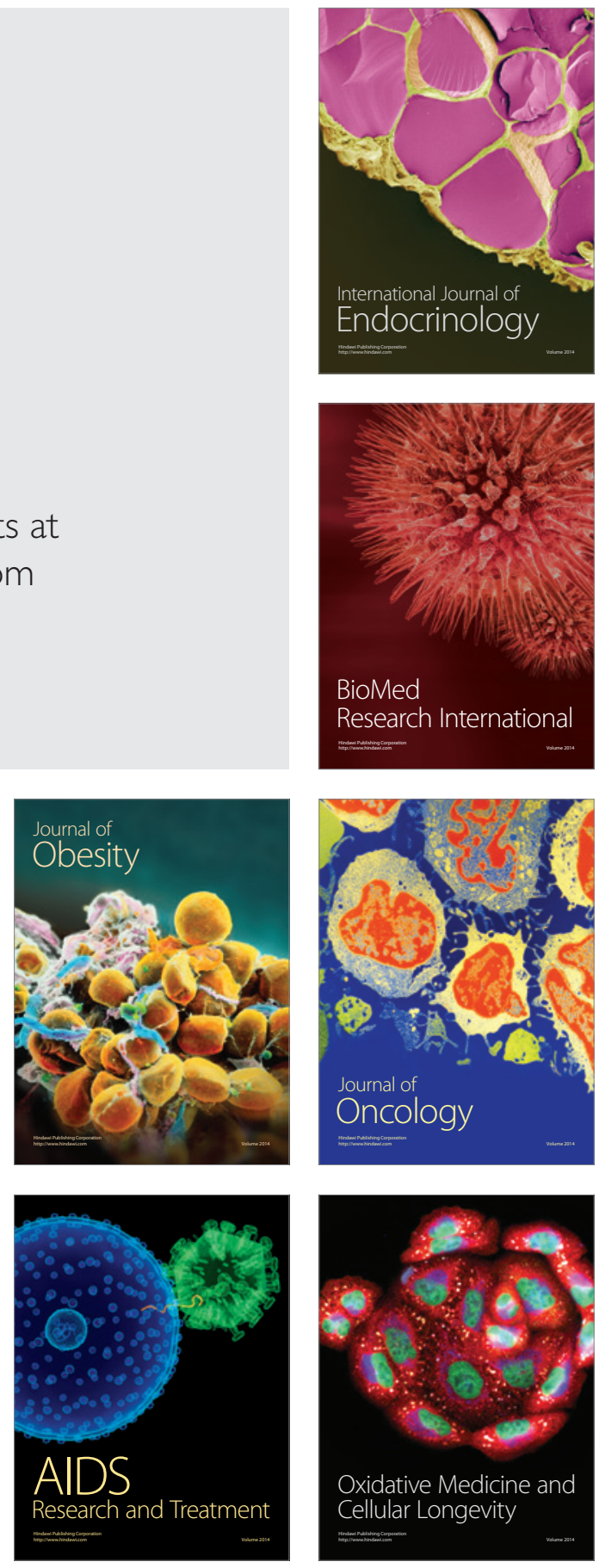